\title{
TEACHERS' DECISION FACTORS IN \\ JUDGING AND PLANNING DISCUSSION ACTIVITIES FOR \\ ELEMENTARY ART PROGRAMS
}

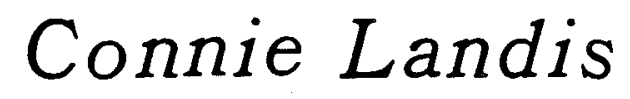

\begin{abstract}
Chapman (1982) has recognized that "the art teacher is relatively free to invent the art curriculum-to determine the objectives, content, and activities made available to children" (p. 107). In the fabrication of the curriculum, the teacher would be influenced by many factors, conceptual and physical in nature. Due to these idiosyncratic constraints and opportunities, the elementary art specialist as well as the regular classroom teacher who teaches art in his or her own classroom are, I maintain, keeping the art curriculum focused on the production of art work in their role as curriculum inventors. This limited view of what constitutes an art curriculum suppresses the potential activities of discussing art work or other objects and events from a variety of perspectives: aesthetic, critical, historical, political, sociological, phenomenological, etc. This narrow view of what an art curriculum is and could be restricts the place of art in the total school program.
\end{abstract}

Johansen (1982) has noted that "talking about art in the classroom is being presented with increasing frequency in art education literature as a significant dimension of education in the visual arts" (p. 13). Many in their own manner have concurred with the importance of broadening studio-production art programs to include more discussion activities: Feldman (1980); Hurwitz and Madeja (1977); Mittler (1980); Perkins (1977); Smith (1968); Stahl and Webster (1978); and others. What those who teach elementary school art consider appropriate discussion topics in talking about art has become the arena for my research. This research is an attempt to study the decision factors or cues revealed by teachers when judging and planning discussion topics for elementary art programs after the proverbial paint jar cover is closed. The study of teacher judgment and planning of activities, whether in art education or another school discipline, comes under the umbrella term of teacher thinking. This paper will provide linkages between teachers' judgment in planning art talk with the available general educational research on teacher thinking. Ideas pertinent to my specific study will conclude the paper.

Since 1975-76 considerable attention and research activity has been directed at the broad educational topic called "teacher thinking" or the "mental life of teachers" (Clark \& Yinger, 1977, p. 278; Clark \& Peterson, in press, p. 1). The topic includes how teachers in varying subject areas and grade levels gather, organize, access, interpret, and evaluate information relevant to teachers' teaching and students' learning. Educational researchers interested in this domain begin from the premise that teachers' behavior in classrooms is in large part determined and influenced by the teachers' thought processes. Many factors impact these teacher thoughts and actions. Through diverse methodologies and study of the widely differing relationships between thought and action as categorized under teacher thinking, these researchers endeavor to construct a composite portrayal of the cognitive psychology involved in teaching. It is intended that this information be utilized in diverse ways by those in the educa-

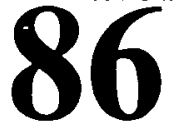


tional community (Clark et al. in press, p. 1). Work within the domain is relevant but not limited to the topics of teacher preservice and inservice training, introducing innovative concepts, materials, and methods into classroom settings, and overall modification of educational practices. Each individual study conducted helps clarify and add to the description of teachers' mental lives necessary for understanding and explaining the form and uses of events occurring in complex classroom situations (p. 1). At this point, however, these early studies cannot be considered "a systematic and cummulative body of research" according to Clark and Peterson (p. 108).

Varied conceptualizations on an organizational framework for the diverse research on teacher thinking have been proposed. Reviews reflect these categorical changes. One early review article by Clark et. al., (1977) classified the teacher thinking research under four major categories: (1) teacher planning, (b) teacher decision making, (c) teacher judgment, and (d) teachers' implicit theories or personal perspectives. Shavelson and Stern (1981) modified these to three, dropping the teachers' theories and perspectives. In the latest review, Clark and Peterson (in press) have not separated teacher judgment as a category "because teacher judgment is but one cognitive process that teachers use in their planning and interactive decision making" (p. 11). Aspects of teacher judgment are thus subsumed under the three categories of teacher planning (including planning with students present and not present in the classroom), teachers' interactive thoughts and decisions, and teachers' theories and beliefs (p. 11).

Clearly, investigation of teachers functioning as judges and planners of aesthetic and critical instructional art activities designed for implementation into elementary classroom situations comes under teacher planning in the Clark and Peterson category. In this study, the judgments made and the plans to be developed before classroom interaction with students by those who teach elementary art will be compared and contrasted. The two teacher populations include the elementary classroom teacher who teaches his or her own art and the art specialist who teaches some or all of the art program.

Five methods of studying and representing teachers' thought processes occur most often in the literature. These include: thinking aloud, stimulated recall, journal keeping, repertory grid, and policy capturing. These are of ten used in varying combinations and supplemented with interviews and field observations. Of these approaches, policy capturing strategies have been recognized as the most frequently utilized method for studying and delineating the judgment topic (Clark, Yinger $\varepsilon$ Wildfong, 1978; Shulman $\varepsilon$ Elstein, 1975). Borrowed from laboratory psychology, the several available policy capturing methods depend least upon the teacher-judges' own reports (Clark et al., in press, p. 15). Reproduction of the inferential response judgments of the particular judge is sought with focus on "how judges weigh and combine information provided by discernible cues in the judgment process" (Clark et al., 1978, p. 1). The cognitive act of judging follows the work of Johnson (1972) and Newell (1968) wherein judgment as a general process involves the evaluation or categorizing of an object or thought. This is logically differentiated from productive thought in that nothing is produced. The material is merely judged, i.e., put in one category or another.

Of particular importance in all policy capturing studies is the accurate 
identification and representation of the decision factors, or cues, which are used by the judges in their judgment tasks. Whether these cues are discerned and structured by the researcher prior to the actual judgment task or evolve from the task itself does not negate the importance of accurate cue specification. Although not many studies using teacher-judges currently exist, individual studies have been done on identifying effective and ineffective teacher characteristics (Anderson, 1977), preinstructional classroom organization and management decisions (Borko, 1978), classroom management (Cone, 1978), instructional content (Floden, Porter, Schmidt, Freeman, $\varepsilon$ Schwille, 1981), reading and mathematics curriculum (Russo, 1978), content of language arts activities (Clark et al., 1978), science curriculum content (Hammond $\varepsilon$ Adelman, 1976), and how teachers use information of varying reliability (Shavelson, Cadwell $\varepsilon \mid z u, 1977$ ). These studies, utilizing one or more of the 5 major methodologies, concentrate either on (a) descriptions and interpretations of the components in the judgment process, (b) accuracy of the judgments made, or $(\mathrm{c})$ investigation of the methodology per se used in studying questions about teacher judgment (Clark, $\varepsilon$ Yinger, 1979, p. 239).

Few, if any studies are concerned with how teachers of art plan; none use these methodologies to illuminate teacher judging and planning as just reviewed. In this descriptive and interpretive study, an attempt will be made to identify and define the important decision factors of the two experienced populations of teachers as they judge and write discussion activities. The research questions central to the study are:

1. What factors do teachers consider when judging aesthetic and critical discussion activities designed for instructional implementation?

2. Upon what factors does a teacher focus when planning activities for talking about art?

3. What if any differences are there among the classroom and art teachers' decision factors in judging and planning activities involving talk about art?

In order to investigate these questions, multiple research perspectives will be utilized as proposed by Sevigny (1981) and Beittel (1973) in other art education studies. First, each group will be asked to write a discussion activity for use with their group of elementary students. These will be analyzed for topic interest. Second, each group will judge a set of written discussion ideas: Each idea centering on one aesthetic or critical inquiry theory such as formalism, phenomenology, imitation, etc. The criteria for developing the set of ideas will follow that proposed by Joyce (1981) for controlling specific content in experimental learning materials. Third, individual teacher interviews will be conducted to arrive at the final configuration or profile of factors for individual teachers and for the two groups. Both the teacher-planned discussion activity and the researcher-designed set will exhibit characteristics which have meanings for the teachers. It is these meanings which help determine the attractiveness of activities to teachers adapting and implementing curriculum materials (Geetz, 1973). Explication of these characteristics and meanings may contribute to further understanding of the complex, demanding and important role of those who teach elementary artof those who are the "ultimate arbiters of classroom practice" (Doyle $\varepsilon$ Ponder, 1977, p. 75). A reduction of the studio-production emphasis toward more talking about art with elementary children is an idea proposed for years, but long over-due in practice.

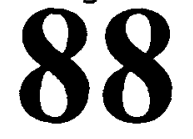




\section{REFERENCES}

Anderson, D.L. (1977). Differences in teachers' judgment policies for varying numbers of verbal and numerical cues. Organizational Behavior and Human Performance, 19, 68-88.

Beittel, K.R. (1973). Alternatives for art education research: Inquiry into the making of art. Dubuque, lowa: Wm.C. Brown Co.

Borko, H. (1978). An examination of some factors contributing to teachers' preinstructional classroom organization andmanagement decisions. Paper presented at the annual meeting of the American Educational Research Association, Tornoto, Ontario.

Chapman, L.H. (1982). Instant art, instant culture: The unspoken policy for American schools. New York: Teachers College Press.

Clark, C.M., \& Peterson, P.L. (in press). Teachers' thought processes. In M.C. Wittrock (Ed.), Handbook of research on teaching, 3rd edition. New York: Macmillan.

Clark, C.M., \& Yinger, R.J. (1977). Research on teacher thinking. Curriculum Inquiry, I (4), 279-304.

Clark, C.M., $\varepsilon$ Yinger, R.J. (1979) . Teachers thinking. In P.L. Peterson $\varepsilon$ H.J. Walberg (Eds.), Research on teaching: Concepts, findings, and implications. Berkeley: McCutcheon Pub. Corp.

Clark, C.M., Yinger, J.J., \& Wildfong, S.C. (1978). Identifying cues for use in studies of teacher iudgment. Washington, D.C.: National Institute of Education (DHEW). (ERIC Document Reproductive Service No. ED 162 982).

Cone, R. (1978). Teachers' decisions in managing student behavior: A laboratory simulation of interactive decision-making by teachers. Paper presented at the annual meeting of the American Educational Reserach Association, Toronto, Canada.

Doyle, W., \& Ponder, G. (1977). The ethic of practicality: Implications for curriculum development. In A. Molnar \& J.A. Zahorik (Eds.), Curriculum theory. Washington, D.C.: Association for Supervision and Curriculum Development.

Feldman, E.B. (1980). Anthropological and historical conceptions of art curricula. Art Education, 33 (6), 6-9.

Floden, R.E., Porter, A.C., Schmidt, W.H., Freeman, D.J., \& Schwille, J.R. (1981). Responses to curriculum pressures: A policy capturing study of teacher decisions about content. Journal of Educational Psychology 73 , 129-141.

Geertz, C. (1973). The interpretation of cultures. New York: Basic Books.

Hammond, K.R., \& Adelman, L. (1976). Science, values, and human judgment. Science, 194, 389-396.

Hurwitz, A. \& Madeja, S.S. (1977). The joyous vision: Source book. Englewood Cliffs, New Jersey: Prentice-Hall, Inc.

Johansen, P. (1982). Teaching aesthetic discerning through dialog. Studies in Art Education, 23 (2), 6-13.

Johnson, D.M. (1972). Systematic introduction to the psychology of thinking. New York: Harper and Row.

Joyce, B.R. (1981). Vehicles for controlling content in the study of teaching. In B.R. Joyce, C.C. Brcwn, \& L. Peck (Eds.), Flexibility in teaching: An excursion into the nature of teaching and training. New York: Longman, Inc.

Mittler, G.A. (1980). Learning to look/looking to learn: A proposed approach to art appreciation at the secondary school level. Art Education, 33 (3), 
17-21.

Newell, A. (1968). Judgment and its representation: An introduction. In B. Kleinmuntz (Ed.), Formal Representation of Human Judgment. New York: John Wiley and Sons.

Perkins, D.N. (1977). Talk about art. Journal of aesthetic education, 11 (2), 87116.

Russo, N.A (1978). Capturing teachers' decision policies: An investigation of strategies for teaching reading and mathematics. Paper presented at the annual meeting of the American Educational Research Association, Toronto, Ontario.

Sevigny, M.J. (1981). Triangulated inquiry - A methodology for the analysis of classroom interaction. In J. Green \& C. Wallet (Eds.) Ethnography and lanquage in educational settings. Norwood, N.J.: Ablex Publishing Corp.

Shavelson, R.J., Cadwell, J., $\varepsilon$ Izu, T. (1977). Teachers' sensitivity to the reliability of information in making pedagogical decisions. American Educational Research Journal, 14, 83-97.

Shavelson, R.T., \& Stern, P. (1981). Research on teachers' pedagogical thoughts, judgments, decisions and behavior. Review of Educational Research, 51, 455-498.

Shulman, L.S., $\varepsilon$ Elstein, A.S. (1975). Studies of problem solving, judgment and decision making: Implications for educational research. In F.N. Kerlinger (Ed.), Review of research in education. Vol iii, Itasca, lllinois: Peacock.

Smith, R. (1968). Aesthetic criticism: The method of aesthetic education. Studies in Art Education, 19 (3), 12-29.

Stahl, R.J., $\varepsilon$ Webster, N.D. (1978). Validating a model for art and aesthetic awareness activities: Results of an experimental study. Studies in Art Education, 19 (2). 